\title{
Catalytic combustion and steam reforming of hydrocarbons in microreactor
}

\author{
Sergey Dimov ${ }^{* 1}$, Ol'ga Gasenko $^{1}$ \\ ${ }^{1}$ Kutateladze Institute of Thermophysics SB RAS, 630090 Novosibirsk, Russia
}

\begin{abstract}
Catalytic combustion of fuel gas using a platinum catalyst was experimentally investigated in the slit microreactor. The composition of the exhaust gases was determined depending on temperature and time of contact. Data of methane steam reforming were received in that reactor with rhodium catalysts depending on temperature for three samples with different composition of doping substances.
\end{abstract}

\section{Introduction}

The development of catalytic combustion technology and steam conversion of natural gas and other hydrocarbon fuels is relevant for the development of environmentally friendly catalytic gas turbine plants, heating devices, hydrogen and syngas production. Catalytic combustion of hydrocarbons has several advantages over flaring. The decrease in the process temperature leads to a significant decrease in the formation of nitrogen oxides, the creation of heat fluxes with lower process temperatures [1]. The importance of studying the oxidation of hydrocarbons in small concentrations is due to the need to solve environmental problems for purification of industrial emissions [2]. A promising solution for hydrogen production was the creation of catalytic reactors based on microchannel technology [3]. Micro-reactors have a number of advantages: high ratio of catalytic surface to volume, high rate of heat and mass transfer, and short contact times. The steam reforming of hydrocarbons and hydrocarbon derivatives in microchannels was experimentally and numerically studied in [4-7]. At the same time, one of the main problems is the search for suitable catalysts for the oxidation of hydrocarbons and steam reforming. These catalysts should have high activity and stability for carrying out reactions at the lowest possible starting temperature and high thermal stability (up to 1350C). The same problem is associated with the search for effective doping additives to increase the activity and stability of the catalyst. Platinum is commonly used to carry out the oxidation of hydrocarbons $[2,8]$. For steam reforming, the choice of catalyst is more problematic, since the process takes place at high temperatures with the absorption of a large amount of heat. The main part of the heat is spent on evaporation of water, heating the steam. According to the data of $[9,10]$, rhodium is the most effective catalyst for steam reforming of methane.

The purpose of this work was to study the oxidation of the propane-butane mixture and the methane steam reforming in slit reactor whose walls are coated with a nanoscale catalyst.

* Corresponding author: dimov@,itp.nsc.ru 


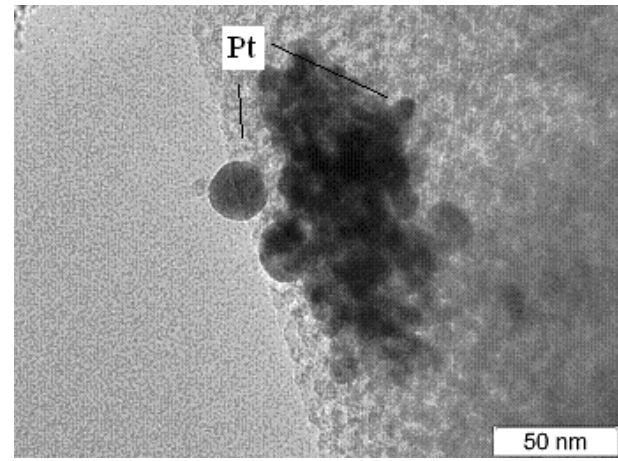

a

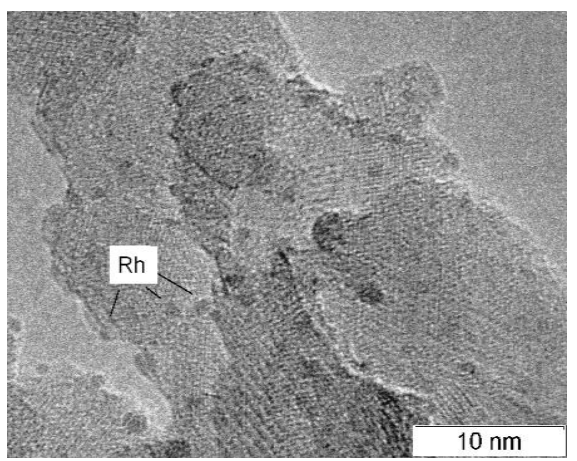

b

Fig. 1. TEM pictures of the catalyst for the oxidation of hydrocarbons (a), steam reforming (b).

\section{The experimental part}

\subsection{Preparation of catalysts}

The use of noble metals as a catalyst enables oxidation of main components of the fuel gas at a temperature of $250-450{ }^{\circ} \mathrm{C}$ and at a temperature of $750-850^{\circ} \mathrm{C}$, steam reforming of methane. The multilayer catalytic coating is based on platinum for the oxidation of hydrocarbons and based on rhodium doped with lanthanum and barium oxides for steam reforming.

The catalyst support, $\gamma-\mathrm{Al}_{2} \mathrm{O}_{3}$, was impregnated with solutions of nitrate salts of lanthanum and barium, subjected to high-temperature calcination at $1050^{\circ} \mathrm{C}$. It was then impregnated with a solution of rhodium nitrate, calcined at $500^{\circ} \mathrm{C}$. The metal rod was treated with acetone for degreasing, etched in $1 \mathrm{M}$ hydrochloric acid at $60^{\circ} \mathrm{C}$. It was then densely coated with titanium oxide from a complex organic solution to prevent oxidation of the metal surface at high temperatures of the steam reforming process [11]. The aerosol spraying procedure of the catalyst was repeated many times until the required weight was reached. In order to avoid cracking of the applied layer, the final calcination was carried out at a rate of temperature rise of not more than $3 \mathrm{C} /$ minute. The procedure for preparing a catalyst for the oxidation of hydrocarbons includes the steps of impregnating alumina with an ammonium complexes of platinum, drying, calcination. The application of the catalyst to the metal rod is similar to the above. Figure 1 shows photographs of the catalyst particles obtained on a transmission electron microscope for combustion (a) and steam reforming (b).

\subsection{Experiment: Oxidation}

Experiments on the oxidation of the propane-butane mixture were carried out using the setup described in [6] for three contact times of 32, 98, and $161 \mathrm{~ms}$. The mixture of fuel gas and air, set by the Bronkhorst gas controllers, was supplied to the preheating chamber and then to the slit annular reactor. In the course of the experiments, gas flow rates, reactor temperatures, and the composition of the inlet and outlet gas mixtures were measured. The temperature of the reactor was measured by a type $\mathrm{K}$ thermocouple. The composition of the output and input gases was analyzed by a chromatograph with a mass selective detector Agilent, as well as a Maestro chromatograph with a thermal conductivity sensor. The necessary temperature of the reactor was created by the degree of heating of the electric 


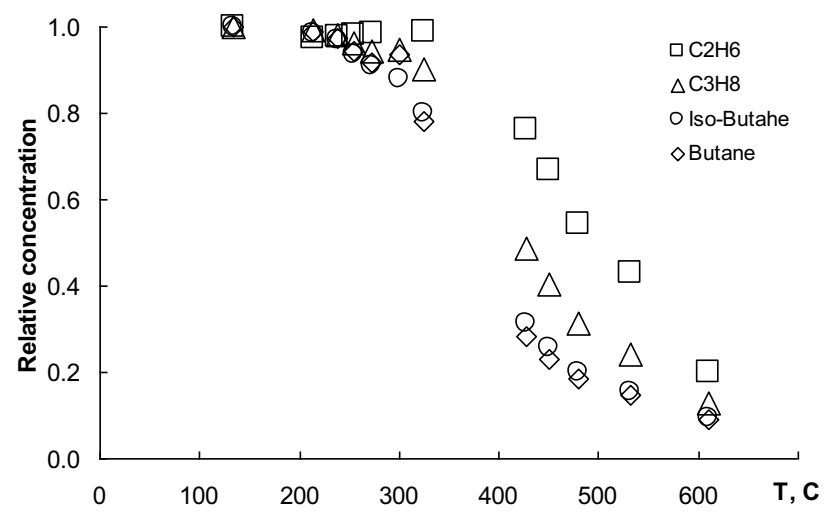

Fig. 2 Dependence of the relative concentrations of output gases normalized to the input from the temperature of the reactor at a contact time of $98 \mathrm{~ms}$.

heater. Figure 2 shows the composition of the exhaust gases after the reactor at different temperatures for a contact time of $98 \mathrm{~ms}$.

The conducted experiments showed high catalytic activity and stability of platinum catalysts on a modified multilayer $\gamma-\mathrm{Al}_{2} \mathrm{O}_{3}$ support. It is found that the main components of the fuel gas (propane and butane) are oxidized at a temperature of 450-500 C with a contact time of $98 \mathrm{~ms}$. An increase in the contact time up to $161 \mathrm{~ms}$ weakly affects the composition of the exhaust gases, and a decrease of up to $32 \mathrm{~ms}$ results in a three-fold deterioration in the oxidation of the fuel gas at the same process temperatures.

\subsection{Methane steam reforming}

The study of methane steam reforming was carried out in an annular microchannel reactor, with a nano-sized catalyst, deposited on the surface of the inner cartridge-cylinder. The technology of the preparation of the catalytic surface is described in [6,7]. In the experiments carried out, the amount of doping additives $\mathrm{La}_{2} \mathrm{O}_{3}$ and $\mathrm{BaO}$ in the catalyst support $\gamma-\mathrm{Al}_{2} \mathrm{O}_{3}$ was changed. The obtained catalyst samples were studied by electron microscopy. In the process of studying chemical transformations, the temperature of the reactor, the contact time, and the composition of the mixture changed. Experiments on methane conversion were carried out with a contact time of 30,60, and $120 \mathrm{~ms}$. The results of the degree of methane conversion for three samples with different composition of doping substances at one contact time $(60 \mathrm{~ms})$ depending on the reactor temperature are shown in Fig. 3. Reducing the concentrations of lanthanum and barium oxides below 1.5 and 1\%, respectively, leads to a decrease in the thermal stability of the catalyst. At high operating temperatures, $\gamma-\mathrm{Al}_{2} \mathrm{O}_{3}$ conversion occurs in high-temperature modifications of the $\alpha$ - and $\theta-\mathrm{Al}_{2} \mathrm{O}_{3}$, leading to sintering and destruction of the catalytic layer. The catalyst with a higher content of lanthanum and barium ( 3 and $2 \%$, respectively) is characterized by a less uniform dispersion of rhodium particles, which also leads to a decrease in catalyst activity due to the sintering of rhodium particles.

\section{Conclusions}

The degree of oxidation of hydrocarbons on a platinum catalyst supported on $\gamma$ alumina in a microchannel was experimentally obtained for different reactor temperatures and contact 


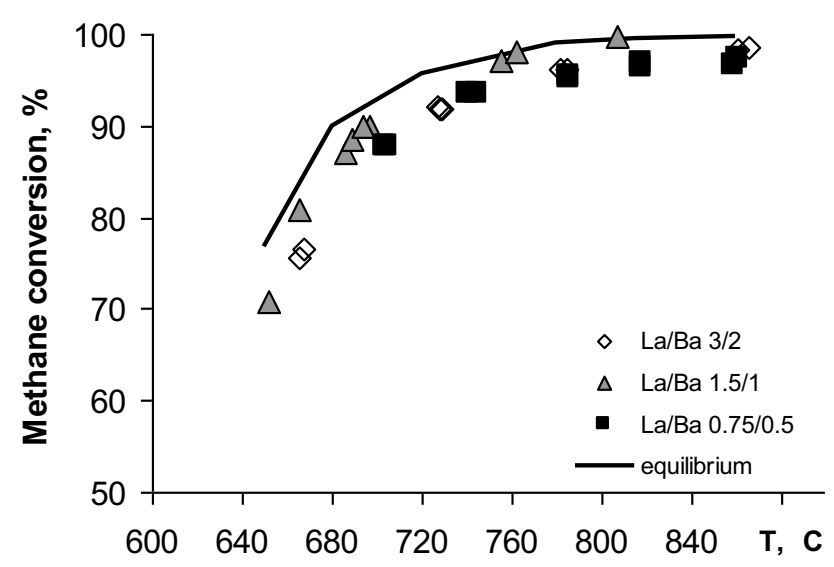

Fig. 3. Steam conversion of methane as a function of reactor temperature with a contact time of 60 $\mathrm{ms}$. The line corresponds to the equilibrium degree of methane conversion.

times. It is shown that there is an optimum degree of doping of alumina with lanthanum and barium oxides for effective steam reforming of methane on a rhodium catalyst.

The research of chapter 2.3 was carried out with the partial support of the Program E2 of the Department of Power Engineering, Mechanical Engineering, Mechanics and Control Processes of the Russian Academy of Sciences.

\section{References}

1. Z.R. Ismagilov, M.A. Kerzhentsev, Cat. Rev: Sci. Eng. 32, 51 (1990)

2. T.G. Alkhazov, L.Ya. Margolis, Moscow, Khimiya Publ. (1985)

3. W. Ehrfeld, V. Hessel, H. Lowe, Microreactors: New technology for modern chemistry (Weinheim:Wiley-VCH, 2000)

4. V.V. Kuznetsov, O.V. Vitovsky, J. Eng. Therm. 17, 191 (2008)

5. V.V. Kuznetsov, O.V. Vitovsky, O.A. Gasenko, Theor. Foun. Chem. Eng. 48, 376 (2014)

6. V.V. Kuznetsov, S.P. Kozlov, J. Eng. Therm. 20, 229 (2011)

7. V.V. Kuznetsov, S.P. Kozlov, J. Eng. Therm. 17, 53 (2008)

8. I.E. Beck, V. I. Bukhtiyarov, I. Y. Pakharukov, V. I. Zaikovsky, V.V. Kriventsov, V.N. Parmon, J. Cat. 268, 60 (2009)

9. M. Maestry, D.G. Vlachos, A. Beretta, G. Groppi, E. Tronconi, J. Cat. 259, 211 (2008)

10. V.V. Kuznetsov, O.V. Vitovsky, O.A. Gasenko, J. Eng. Therm. 18, 187 (2009)

11. V.V. Kuznetsov, O.V. Vitovsky, O.A. Gasenko, Pat. \#2549619 Rus. Fed. (2015) 